\title{
Beta-adrenergic blockade in the management of acute thyrotoxic crisis, tachycardia and arrhythmias
}

\author{
Victor Parsons \\ D.M., M.R.C.P. \\ Senior Lecturer
}

\author{
DAVID JEWITT* \\ B.Sc., M.R.C.P. \\ Lecturer in Medicine
}

Department of Medicine, King's College Hospital, London, S.E.5

TACHYCARDIn is a characteristic feature of thyrotoxicosis at all ages, but the older the patient the more frequent the occurrence of atrial fibrillation. Treatment of thyrotoxicosis is followed by slowing of heart rate and more than half of the thyrotoxic patients with atrial fibrillation, who are treated with anti-thyroid drugs or surgery (Sandler \& Wilson, 1959) or radioactive iodine therapy (Staffurth, Gibberd \& Hilton, 1965) revert to sinus rhythm. Until thyrotoxicosis is controlled the tachycardia is resistant to digitalis therapy unless a larger dose is employed (McMichael, 1963) and this feature may itself indicate the diagnosis of occult thyrotoxicosis (Cookson, 1959). Even shifts in the protein-binding of thyroxine may play a part in supraventricular tachycardias (Schatz, 1967). The circulatory features of thyrotoxicosis are usually a marked feature of the thyrotoxic crisis or storm, when tachycardia is associated with hyperpyrexia, diarrhoea, psychiatric disturbance, muscle weakness and profuse sweating (Ingbar, 1966).

Urgent control of the tachycardia, cardiac arrhythmias and the hypermetabolic state are occasionally required, notably when a fully established crisis develops. In this situation blockade of the sympathetic nervous system or depletion of tissue stores of catecholamines may be of value. The first reports of a striking improvement in patients with thyrotoxic crisis were those treated by epidural block (Crile, 1929) and later using spinal anaesthesia (Knight, 1945). It was suggested that the circulatory changes were due to increased peripheral responsiveness to catecholamines (Brewster et al., 1956), no evidence being found for an absolute increase in their output (Wisewell et al., 1963). Reserpine was found to be effective in controlling thyrotoxic symptoms (Canary et al., 1959) and sympathetic blockade by guanethidine has been used increasingly (Degroot et al., 1961 ; Leak, 1963 ; Waldstein et al., 1964) with similar success. Recently propranolol has been tried in thyrotoxic tachycardia,

\footnotetext{
*Present appointment: Senior Registrar, Department of Medicine, Hammersmith Hospital.
}

arrhythmia and tremor (Rowlands, Howitt \& Markham, 1965 ; Howitt \& Rowlands, 1966).

The pharmacology of sympathetic-blocking drugs in thyrotoxicosis has been recently reviewed (Harrison, 1964).

Encouraged by these reports we first used pronethalol and later propranolol to treat the occasional thyrotoxic patient who required urgent control of tachycardia, cardiac arrhythmia and the hypermetabolic state.

\section{Clinical groups studied}

(1) Patients in a thyrotoxic crisis or 'storm'.

(2) Patients with thyrotoxicosis who presented with disabling tachycardia, arrhythmia, or palpitations pending response to antithyroid drugs.

(3) Patients whose thyrotoxicosis was associated with an independent cardiac lesion.

(4) Thyrotoxic patients requiring urgent surgical operation before control could be achieved by routine anti-thyroid measures.

\section{Thyrotoxic crisis}

(1) S.B., a 40-year-old motor mechanic, who had a goitre at the age of 12 , developed acute thyrotoxicosis at the age of 38 , with loss of weight, severe tremor and dyspnoea on exertion. He was given Lugol's iodine in preparation for thyroidectomy but improvement was so encouraging that he declined surgery, and defaulted from supervision for 2 years, taking iodine regularly. When seen again he had a very large nodular goitre and was mildly thyrotoxic with a regular pulse rate of $100 / \mathrm{min}$. Further preparation was attempted but control was difficult ; finally sub-total thyroidectomy was carried out, followed 3 days later by a thyrotoxic crisis, hyperpyrexia, disorientation, dyspnoea and atrial flutter of $330 / \mathrm{min}$ with $2: 1$ block. In the next 4 days he received $7 \mathrm{mg}$ of digoxin and $1.5 \mathrm{~g}$ of quinidine with no obvious improvement; atrial flutter remained at $320 / \mathrm{min}$ with the block alternating between $2: 1$ and $4: 1$. After $600 \mathrm{mg}$ of pronethanol in $24 \mathrm{hr}$ the pulse rate had fallen to $80 / \mathrm{min}$ and an ECG showed 
sinus rhythm. He was maintained on $600 \mathrm{mg}$ of pronethanol daily for a further 2 weeks and although the immediate decrease in pulse rate, hyperpyrexia and general excitement were the only objective signs of improvement, they were immediate and thought not to be due only to thyroidectomy.

(2) I.W., a 35-year-old housewife, was admitted to an observation ward with an acute agitated depression. She volunteered a long history of anxiety and distress with acute symptoms for 5 weeks. Three years previously she had refused thyroidectomy at another hospital and had taken medication sporadically; owing to her psychiatric state, both her children had been taken into care. On examination she was extremely agitated and emotionally labile; her hands were tremulous and sweating; there were no eye signs. She had a large smooth goitre with a retrosternal projection. Pulse varied between 160 and $120 / \mathrm{min}$, sinus rhythm. Blood pressure $128 / 85$ with no signs of heart failure. Investigations: protein bound iodine $11.6 \mu \mathrm{g} / 100 \mathrm{ml}$. ECG: sinus tachycardia$140 / \mathrm{min}$. Before transfer to a general hospital she had been under sedation with chlorpromazine, $75 \mathrm{mg} /$ day; this was discontinued for 2 days without much change in her condition. Propranolol was given, $120 \mathrm{mg} / \mathrm{day}$ for $48 \mathrm{hr}$ and then $60 \mathrm{mg}$ for $72 \mathrm{hr}$. There was an immediate fall in pulse rate to $90 / \mathrm{min}$ although tremor continued. Her agitation improved considerably at the same time as her tachycardia decreased. An anti-thyroid drug, carbimazole, $60 \mathrm{mg} / \mathrm{day}$, was commenced at this stage and propranolol discontinued owing to gastric discomfort and the development of venous thrombosis. Her tachycardia rebounded to $140 /$ min and came slowly under control over a week on the re-introduction of chlorpromazine, $75-125 \mathrm{mg} /$ day. A further relapse of her agitation and tachycardia to $120 / \mathrm{min}$ responded to the addition of reserpine $0.5 \mathrm{mg} /$ day for a further 10 days. Thyroidectomy was carried out 8 weeks later, a gland of $280 \mathrm{~g}$ being removed without mishap.

(3) J.R., a 28-year-old business representative, presented with a history of slight protuberance of one eye for 6 weeks, loss of weight and mild anxiety. There was no family history of thyroid disorder, nor personal history of mental illness. On examination there was slight lid-lag but no exophthalmos, a regular tachycardia of $90 / \mathrm{min}$ and slight goitre but no bruit. Investigation showed a serum PBI of $15.4 \mu \mathrm{g} / 100 \mathrm{ml}$. He was treated with mild sedation and $45 \mathrm{mg}$ of carbimazole a day in preparation for surgery if his exophthalmos did not become acute. While an out-patient 3 weeks later he discontinued his anti-thyroid medication because of a slight rash over his thighs. He did not return for 2 weeks, being away on business. He was then admitted in thyroid crisis with an acute psychosis characterized by derealization, hallucinations and ideas of reference with paranoid features. $\mathrm{He}$ ran a fever of $38.5^{\circ} \mathrm{C}$ and a tachycardia of $110 / \mathrm{min}$, regular rhythm, having lost $3 \mathrm{~kg}$ in weight. Treatment was started with $60 \mathrm{mg}$ of propranolol and $300 \mathrm{mg}$ of chlorpromazine a day. Within $48 \mathrm{hr}$ all the features of the psychosis had gone, the tachycardia was reduced to $90 / \mathrm{min}$ and his pyrexia had subsided. An anti-thyroid drug, methylthiouracil, $600 \mathrm{mg} /$ day, was introduced 2 days later without a recurrence of the rash and his thyrotoxicosis came under control slowly within 2 weeks, propranolol and chlorpromazine being discontinued at this time.

(4) C.B., a single 35-year-old brewery worker, was troubled by a swelling in his neck for 5 years, with dyspnoea at night for some weeks. In his past he had had meningitis as a child, which had left him mentally defective. There was no family history of thyroid disease. On examination he was of muscular physique with no signs of thyrotoxicosis; no deafness could be detected on simple questioning. A large goitre in the neck caused stridor on acute flexion or extension of the neck, there being a retrosternal projection. Pulse $85 / \mathrm{min}$ (sleeping), blood pressure 130/80. Indirect laryngoscopy revealed a polypoid keratinized mass on one vocal cord accounting for part of his stridor. Investigation revealed a normal ${ }^{131}$ I uptake, which was evenly distributed across the gland. He was admitted and received Lugol's iodine for 2 days prior to surgery. A large colloid goitre was removed without incident. Within $24 \mathrm{hr}$ he suddenly became dyspnoeic, pulse $144 / \mathrm{min}$, sinus rhythm, pryexia to $101^{\circ} \mathrm{F}$ with gross tremor, sweating and mild anxiety. Investigations at this time revealed a PBI of $10.5 \mu \mathrm{g} / 100 \mathrm{ml}$ but a butanol EI of only $1 \mu \mathrm{g} / 100 \mathrm{ml}$, and VMA excretion of $9.9 \mathrm{mg}$ in $24 \mathrm{hr}$. Chest X-ray: some basal congestion but no signs of heart failure. Serum electrolyte concentrations normal. He received propranolol, $20 \mathrm{mg}$ t.d.s. In less than $4 \mathrm{hr}$ the pluse rate and pyrexia had subsided and he was much calmer. Electrocardiograms taken at the time and later showed no evidence of arrhythmia.

\section{Patients with tachycardia and arrhythmia}

Because of the encouraging results in the treatment of the acute tachycardia and arrhythmia accompanying thyrotoxic crisis it was thought worthwhile to try the effects of sympathetic betablocking agents in a number of patients who had 
no features of crisis or concurrent myocardial disease, and before their thyrotoxicosis came under anti-thyroid drug control. The results are shown in Table 1. In almost every patient within $72 \mathrm{hr}$, and in many patients within $48 \mathrm{hr}$, there had been a reduction in pulse rate but in only four of the ten with fibrillation was there a reversion to sinus rhythm. One patient (F.W.), who stopped taking pronethanol, developed atrial fibrillation again but with the re-introduction of the drug was in sinus rhythm within $24 \mathrm{hr}$.

\section{Patients with concomitant and independent heart disease}

(1) T.D., aged 60, was known to have had pernicious anaemia in 1945. He presented in June 1965 with a paroxysm of atrial fibrillation but at this time full investigation did not support a diagnosis of thyrotoxicosis. In July 1966 he developed severe retrosternal chest pain and an electrocardiogram showed a transmural anterolateral myocardial infarct which was confirmed by peak elevation of the serum glutamic oxaloacetic transaminase to 150 units $/ \mathrm{ml}$ (normal range 5-30 units $/ \mathrm{ml}$ ). He was noted to have lost $20 \mathrm{lb}$ in weight despite a good appetite and on examination had a sinus tachycardia of $110 / \mathrm{min}$ with warm moist skin and a nodular goitre. A PBI of $10 \cdot 6 \mu \mathrm{g} / 100 \mathrm{ml}$ with a rapid ${ }^{131} \mathrm{I}$ uptake confirmed a diagnosis of acute active thyrotoxicosis.

On the 2nd day of his admission atrial fibrillaation developed with a ventricular rate of $200 /$ min. He was, therefore, treated with intravenous propranolol, $10 \mathrm{mg}$ over $30 \mathrm{~min}$, and maintained on $20 \mathrm{mg}$ orally 6-hourly. Five hours after starting therapy he reverted to sinus rhythm. After 1 week's therapy with propranolol the cardiovascular manifestations of his thyrotoxicosis had disappeared. He then commenced carbimazole $15 \mathrm{mg}$, q.d.s. On the 11th day after starting propranolol, he developed mild left ventricular failure, which responded rapidly to intravenous frusemide, the propranolol having been stopped for 2 days. During this period atrial fibrillation recurred but following the re-introduction of propranolol sinus rhythm returned within 12 hours. $\mathrm{He}$ was then given digitalis in full dosage, and 1 month later, having made a good recovery from his myocardial infarct and when he was clinically enthyroid, the propranolol was discontinued and he continued to take carbimazole alone.

(2) H.C. at the age of 16 years had Sydenham's chorea with evidence of rheumatic carditis. She was admitted in June 1966, aged 46 years, as an emergency with a history of tiredness, irritability, loss of weight, ankle swelling and dyspnoea on exertion. Her own general practitioner had given digitalis orally before admission but had been unable to slow her ventricular rate. On examination she was dyspnoeic and had atrial fibrillation with a ventricular rate of $160 / \mathrm{min}$. She had signs of moderate mitral stenosis and was in mild congestive failure. Twelve hours after admission she developed a right femoral arterial occlusion due to embolism. This was removed at operation under local anaesthesia. Her ventricular rate remained uncontrolled despite full administration of digitalis which raised the possibility of co-existent active thyrotoxicosis which was confirmed by a PBI of $13.9 \mu \mathrm{g} / 100 \mathrm{ml}$ and a rapid ${ }^{131}$ I uptake by her thyroid. Propranolol was therefore added in a dose of $20 \mathrm{mg}$ q.d.s. This resulted in slowing of her ventricular rate although atrial fibrillation persisted. One week after admission when she was much improved, carbimazole was begun and over the next month her pulse rate settled and her irritability cleared. When seen 3 months after her initial admission the pulse had reverted to sinus

TABLE 1

Patients with tachycardia or arrhythmia treated with B-blockade

\begin{tabular}{|c|c|c|c|c|c|c|c|c|}
\hline \multirow{2}{*}{$\begin{array}{l}\text { Patient } \\
\text { F.W. }\end{array}$} & \multirow{2}{*}{$\begin{array}{r}\text { Age } \\
57\end{array}$} & \multirow{2}{*}{$\begin{array}{c}\text { Sex } \\
M\end{array}$} & \multirow{2}{*}{$\begin{array}{c}\begin{array}{c}\text { Pulse rate } \\
\text { before }\end{array} \\
\text { AF } 125\end{array}$} & \multicolumn{2}{|c|}{$\begin{array}{c}\text { Pulse rate } \\
72 \mathrm{hr} \\
\text { later }\end{array}$} & \multicolumn{2}{|c|}{$\begin{array}{r}\text { B-blocker } \\
\text { (mg/day) }\end{array}$} & \multirow{2}{*}{$\frac{\begin{array}{l}\text { Digoxin } \\
\text { (mg/day) }\end{array}}{\mathrm{Nil}}$} \\
\hline & & & & SR & 80 & $\mathbf{P}$ & 600 & \\
\hline M.T. & 66 & $\mathrm{~F}$ & AF $\quad 80$ & $\mathrm{AF}$ & 55 & $\mathbf{P}$ & 600 & 0.5 \\
\hline S.B. & 58 & $\mathbf{M}$ & AF $\quad 90$ & AF & 77 & $\mathbf{P}$ & 600 & Nil \\
\hline W.B. & 23 & $\mathrm{~F}$ & AF 100 & $\mathrm{AF}$ & 100 & $\mathbf{P}$ & 600 & Nil \\
\hline K.P. & 62 & $\mathrm{~F}$ & AF 74 & $\mathrm{AF}$ & 72 & $\mathbf{P}$ & 600 & 0.5 \\
\hline V.C. & 57 & $\mathrm{~F}$ & AF 150 & SR & 75 & $\mathbf{P}$ & 600 & 0.75 \\
\hline V.W. & 40 & M & AF 176 & $\mathrm{AF}$ & 86 & I & 60 & 0.75 \\
\hline M.M. & 46 & F & SR 125 & SR & 83 & I & 60 & 0.75 \\
\hline T.P. & 65 & M & AF 153 & SR & 42 & I & 60 & 0.75 \\
\hline M.P. & 75 & $\mathrm{~F}$ & AF 120 & AF & 80 & I & 60 & 0.5 \\
\hline O.S. & 57 & $M$ & SR 120 & SR & 90 & I & 60 & Nil \\
\hline B.L. & 20 & $\mathbf{M}$ & AF 120 & SR & 80 & I & 60 & Nil \\
\hline
\end{tabular}

$\mathrm{SR}=$ sinus rhythm; $\mathbf{A F}=$ artial fibrillation; $\mathbf{P}=$ Pronethanol; $\mathrm{I}=$ Inderal (propranolol). 
rhythm and propranolol was stopped, but she continued with digoxin, carbimazole and phenindione. She is shortly to have a mitral valvotomy.

Emergency surgery in uncontrolled thyrotoxicosis

A typical case is O.S., a 53-year-old nurseryman, who had noticed swelling of his eyelids, loss of weight and moderate tremor for 9 months. $\mathrm{He}$ had only received intermittent anti-thyroid treatment. His eyesight had deteriorated, corneal ulceration had set in and tarsorrhaphies had broken down. He was admitted for possible orbital decompression, on account of malignant exophthalmos, severe ulceration and corneal damage. Investigations revealed a pulse rate of $110 / \mathrm{min}$, sinus rhythm, $4 \mathrm{~mm}$ of exophthalmos and a moderate goitre. In view of the degree of conjunctival sepsis preliminary tarsorrhaphy was attempted. Anti-thyroid drugs were introduced again with propranolol $20 \mathrm{mg}$ t.d.s. and surgery was carried out under nitrous oxide, oxygen, pentothal and halothane. He suffered severe hypotension for $24 \mathrm{hr}$ following this minor operation as the only complication.

\section{Discussion}

In four patients with thyroid crisis the psychiatric symptoms and circulatory changes were successfully controlled by the use of propranolol. It might be argued that in a fluctuant condition like thyrotoxicosis they might have responded to bed-rest and sedation alone, but this seems unlikely since the half-life of thyroxine in the plasma is known to be approximately $72 \mathrm{hr}$ (Oddie, Meade \& Fisher, 1966). The mechanism of action of propranolol in reversing the psychiatric features of these cases may represent blockade of adrenergic receptors in the peripheral sympathetic nervous system or an additional direct central effect. Studies of the central nervous system (CNS) effects of catecholamine infusions made directly into the cerebral circulation of chicks were unable to demonstrate evidence of $\beta$-receptor blockade by propranolol in this preparation above the level of the midbrain (Dewhurst \& Marley, 1965). Conversely with higher dosage of propranolol in rats an anti-convulsant property and a CNS depressant effect emerged attributable to $\beta$-blockade (Murman, Almirante \& Saccani-Guelfi, 1966). It is of interest that in three of these patients the acute crisis was brought on by neglect of appropriate treatment due to default or psychiatric disturbance making drugtaking sporadic. Clearly earlier suspicion of this would have warranted hospital admission for control.

The anti-arrhythmic properties of propranolol were important in all four groups of patients. At the experimental level there is evidence that propranolol reduces the rate of rise and height of the cardiac muscle action potential, the effect being the complete reverse of that produced by sympathetic stimulation (Vaughan Williams, 1966). This action involves a reduction in the normally explosive increase of sodium conductance associated with depolarization like the action of a local anaesthetic agent (Morales-Aguilera \& Vaughan Williams, 1965), but part of the antiarrhythmic action may be due to a direct action on the specialized conducting tissues which is only apparent in higher dosage than that required to produce $\beta$-adrenergic blockade (Lucchesi, 1965). The clinical value of propranolol in controlling thyrotoxic arrhythmias had been described (Rowlands et al., 1965), despite the absence of effects on the cardiac output and vasodilation in induced thyrotoxicosis (Wilson, Theilen \& Fletcher, 1964).

The two patients with independent cardiac lesions associated with active thyrotoxicosis present special problems. For acute myocardial infarction has only rarely been described in association with active thyrotoxicosis, there being less than twenty well-documented cases in the literature (Grytting \& Salvesen, 1957; Burstein, Lamberg \& Erämaa, 1960; Gordon \& Lenkel, 1964). In the case described here rapid atrial fibrillation developed in the first $24 \mathrm{hr}$ after infarction, a time when this complication would not be unusual in any patient with myocardial infarction. However, we consider that thyrotoxicosis was an important additional precipitating factor in view of this patient's past and subsequent history. Rapid control of arrhythmia and other features of his thyrotoxicosis were achieved by propranolol. The second patient in this group who had mitral stenosis and rapid atrial fibrillation improved dramatically as her ventricular rate slowed. The beneficial effect of propranolol in patients with rheumatic mitral stenosis and atrial fibrillation, where the presence of a rapid ventricular response further limits ventricular filling and causes additional elevation of left atrial pressure, has been recorded (Rowlands et al., 1965). Clearly in this patient thyrotoxicosis was of secondary importance in accounting for persistence of her rapid arrhythmia and precipitation of cardiac failure.

The urgent control of thyrotoxicosis in the patient who required emergency surgery is important, since thyrotoxicosis is said to lead to increased sensitivity to circulating catecholamines released by the induction of general anaesthesia and in response to surgical trauma, which will therefore carry an increased risk of dangerous cardiac arrhythmias during the immediate operative period. 
In the patients treated with propranolol to reverse the circulatory manifestations of thyrotoxicosis digitalis preparations were also given simultaneously if cardiac failure was present or seemed likely to develop. In the patient with the myocardial infarct, failure developed on the 11th day and it seems probable that depression of myocardial contractility by propranolol was responsible for this. Prompt recovery followed removal of propranolol and when it was restarted, this time in combination with digoxin, failure did not recur. Because of this risk of failure developing on propranolol, we would advise simultaneous digitalization in all cases.

Information about the modes of action of catecholamines, thyroxine, digitalis and propranolol on the myocardium and their interactions remains fragmentary. The present state of knowledge is summarized in Fig. 1. It is apparent that

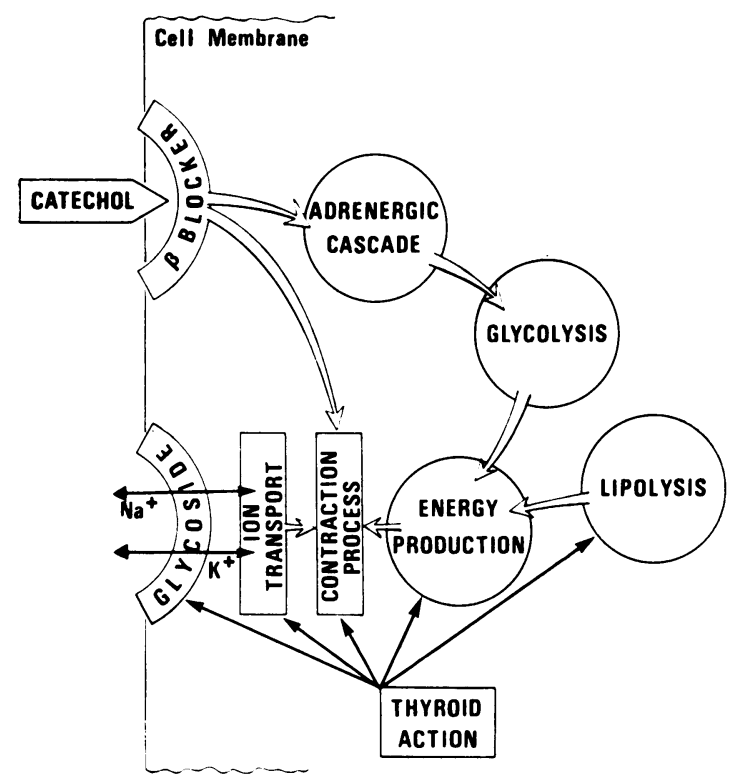

FIG. 1. Thyroid, catechol and glycoside interactions.

catecholamines, whether released by nerve impulses or injected, stimulate the membrane enzyme adenine cyclase which in the presence of magnesium catalyses the intracellular formation of cyclic 3,5-adenosine monophosphate which initiates the cardiac contractile process and activates the enzyme phosphorylase. This series of reactions has been called the adrenergic cascade (Bowness, 1966), the end result being a stimulation of glycolysis with a release of adenine nucleotides and inorganic phosphate (Williamson, 1966). $\beta$ receptor blockade with pronethalol has been shown to block the accumulation of 3,5-AMP and the inotropic response to adrenaline in the isolated rat heart (Robinson et al., 1965).

Digitalis glycosides probably achieve their effects by altering the sensitivity of a sodiumactivated ATPase in the cell membrane so modifying the activity of the energy-dependent sodium pump. Since thyroxin in experimental tissues has been shown to increase sodium transport (Green \& Matty, 1963) possibly the antagonism of thyroxine to the action of digitalis occurs at the level of a membrane ATPase. Digoxin metabolism is altered in thyrotoxicosis: serum is cleared more rapidly of injected labelled digoxin without it appearing in the urine or being more tightly bound to the cellular membranes (Doherty \& Perkins, 1966). It is both these effects which probably explain the experimental finding, that during the continuous infusion of digoxin there is antagonism to its inotropic action and its ability to produce multiple premature beats in hyperthyroidism (Morrow, Gaffney \& Braunwald, 1963).

The mode of action of thyroxine may well be at multiple sites in the cell (Fig. 1) and there is no evidence that it acts via the adrenergic cascade or by inactivating the enzymes, monoamine oxidase or $o$-methyltransferase responsible for the breakdown of catecholamines (Svedmyr \& Waldeck, 1965). There is evidence that the action of adrenalin on glycolysis is not so effective in the absence of thyroid hormones in isolated tissues and it seems that the uncoupling action of thyroxine may allow glycolysis under the stimulus of adrenalin to proceed at a faster rate (possibly by the deinhibition of the latter pathway by a more active Krebs cycle) (Svedmyr, 1966). Further evidence in diaphragm preparations from thyroxine-treated rats shows that the increased lactate production cannot be explained on the basis of glycolysis alone and must be related to increased lipolysis. This is reflected in higher nonesterified fatty acid concentrations found in thyrotoxicosis (Gompertz \& Greenbaum, 1966). This increased flux of free fatty acids is known to inhibit the controlling enzyme phosphofructokinase allowing a pile-up of hexose monophosphates prior to this step in the Embden-Meyerhof pathway, halting the direct conversion of glycogen to pyruvate (Bressler \& Wittals, 1966). It is alterations at this level that are probably related to the inotropic effects of thyroxine and the interaction between $\beta$-blockers and digoxin which are now being recorded (Tuttle \& Innes, 1966).

The use of sympathetic $\beta$-blockade seems to have advantages in acute thyrotoxicosis over the use of a peripheral blocker, guanethidine, with its risk of hypotension and reserpine with the 
possibility of acute catecholamine and serotonin release from tissues (Blumenthal, Davies \& Doe, 1965).

The risk of producing cardiac failure with propranolol exists, although we have only induced it on one patient who also had myocardial infarction. However, we would advise simultaneous digitalization to counteract the decreased myocardial contractibility which propranolol produces.

In conclusion we feel that $\beta$-adrenergic blockade is a useful addition to the treatment of thyrotoxicosis when urgent control is required as in thyrotoxic crisis, patients requiring emergency surgery, patients with disabling cardiovascular manifestations or in patients with additional independent cardiac lesions.

\section{Summary}

A series of patients with thyrotoxicosis have been treated with the $\beta$-blockers, pronethanol and propranolol. Particular benefit has been found in the control of tachycardia and arrhythmias with rapid control of rate and in a proportion reversion to sinus rhythm before the thyrotoxicosis has been alleviated. Thyrotoxic crisis with its added psychiatric complications has also been brought under rapid control. Patients with thyrotoxicosis and concomitant myocardial disease have benefited from a reduction in pulse rate, with the possible complication of heart failure counteracted with the use of digoxin. The metabolic interactions of catecholamines, thyroxine and digoxin are briefly reviewed.

\section{Acknowledgments}

The authors wish to thank Dr W. A. Bourne and Dr R. Kemball Price of the Royal Sussex County Hospital for their help and advice with patients under their care. We are also grateful to $\mathrm{Mr}$ L. Lauste, Mr A. J. Heriot, Mr T. K. Lyle and $\mathrm{Mr} \mathrm{J}$. L. Dawson for referring patients with thyroid disease complicating surgery. We are indebted to Professor J. Anderson for criticism and encouragement, and to Mrs M. Gunns and the Research Funds of King's College Hospital for secretarial assistance.

\section{Generic and Trade Names of Drugs}

Nethalamide: Pronethanol.

Propranolol: 'Inderal.'

\section{References}

Blumenthal, M., Davies, R. \& Doe, R.P. (1965) Carcinoid syndrome following reserpine therapy in thyrotoxicosis. Arch. intern. Med. 116, 819.

BownESS, J.M. (1966) Epinephrine cascade reaction and glycogenolytic effect. Science, 152, 1371.

Bressler, R. \& Wittals, B. (1966) The effect of thyroxine on lipid and carbohydrate metabolism in the heart. J. clin. Invest. 45, 1326.
Brewster, W.R., IsAacs, J.P., Osgood, P.F. \& KING, T.L. (1956) Haemodynamic and metabolic inter-relationships in activity of epinephrine, nor-epinephrine and thyroid hormones. Circulation, 13, 1.

Burstein, J., Lamberg, B.A. \& EramaA, E. (1960) Myocardial infarction in thyrotoxicosis. Acta med. scand. 166, 379.

Canary, J.J., Schaff, M., Duffy, B.J. \& Kyle, L.H. (1959) The effects of oral and intramuscular administration of reserpine in thyrotoxicosis. New Engl. J. Med. 257, 435.

Cookson, H. (1959) The thyroid and the heart. Brit. med.J. i, 254.

CRILE, G. (1929) The interdependence of the thyroid adrenals and nervous system. Amer. J. Surg. 6, 616.

Degroot, W.J., Leonard, J.J., Paley, T.E., Johnson, J.E. \& WARREN, I.V. (1961) The importance of autonomic integrity in maintaining the hyperkinetic circulatory dynamics of human hyperthyroidism. J. clin. Invest. 40, 1033.

Dewhurst, W.G. \& Marley, E. (1965) The effects of $\alpha$-methyl derivatives of nor-adrenalin, phenylethylanine and tryptamine on the central nervous system of chicken. Brit. J. Pharmacol. 25, 705.

DoherTy, J.E. \& Perkins, W.H. (1966) Digoxin metabolism in hypothyroidism and hyperthyroidism. Ann. intern. Med. 64, 489.

GompertZ, D. \& Greenbaum, A.L. (1966) Effects of thyroxine in the pattern of free fatty acid metabolism. Biochim. biophys. Acta, 116, 441.

Gordon, J.A.L. \& Lenkel, S.C.M. (1964) Thyrotoxicosis associated with myocardial infarction. Canad. med. Ass. J. 90, 1128.

GreEN, N.K. \& MATty, A.J. (1963) Action of thyroxine on active sodium transport in isolated membranes of Bufo bufo. Comp. Endocrinol. 3, 244.

Grytting, G. \& SAlvesen, H.A. (1957) Thyrotoxicosis and myocardial infarction. Acta med. scand. 157, 169.

HARRISON, T.S. (1964) Adrenal medullary thyroid relationships. Physiol. Rev. 44, 161.

HowITT, G. \& Rowlands, D.J. (1966) $\beta$-Sympathetic blockade in hyperthyroidism. Lancet, $\mathbf{i}, 628$.

INGBAR, S.H. (1966) The management of thyrotoxic storm. New Engl. J. Med. 274, 1252.

KNIGHT, R.T. (1945) The use of spinal anaesthesia to control sympathetic overactivity in hyperthyroidism. Anaesthesiology, 6, 225.

LEAK, D. (1963) Adrenergic blockade and thyrotoxicosis. Acta endocr. (Kbh.), 43, 131.

LUCCHESI, B.R. (1965) The effects of pronethalol and its dextroisomer upon experimental cardiac arrhythmias. J. Pharmacol. exp. Ther. 148, 94.

McMichael, J. (1963) The heart and digitalis. Brit. med. J. ii, 73.

Morales-Aguilera, A. \& Vaughan Williams, E.M. (1965) The effects on cardiac muscle of $\beta$ receptor antagonists in relation to their activity as local anaesthetics. Brit. $J$. Pharmacol. 24, 332.

Morrow, D.H., Gaffney, T.E. \& Braunwald, E. (1963) Studies on digitalis. VII. Influence of hyper and hypothyroidism on the myocardial response to ouabain. $J$. Pharmacol. exp. Ther. 140, 324.

Murman, D.H., Almirante, L. \& Saccani-Guelfi, $M$. (1966) Central nervous system effects of four $\beta$-adrenergic receptor blockers. J. Pharm. Pharmacol. 18, 318.

Oddie, T.H., MEADE, J.H. \& Fisher, D.A. (1966) Thyroxine turnover in human subjects. J. clin. Endocr. Metab. 26, 425.

Robinson, G.A., Butcher, R.W., Oye, I., Morgan, H.E. \& Sutherland, E.W. (1965) The effect of epinephrine on adenosine $3^{\prime} 5^{\prime}$ phosphate levels in the isolated perfused rat heart. Mol. Pharm. 1, 168. 
Rowlands, D.J., HowitT, G. \& Markham, P. (1965) Propranolol (Inderal) in disturbance of cardiac rhythm. Brit. med. J. i, 891.

SANDLER, G. \& Wilson, G.M. (1959) The nature and prognosis of heart disease in thyrotoxicosis. Quart. J. Med. N.S. 28, 347.

SChATZ, D.L. (1967) Serum free thyroxine and thyroxine binding protein studies in patients with supraventricular tachycardias. J. clin. Endocr. Metab. 27, 165.

Staffurth, J.S., Gibberd, M.C. \& Hilton, P.J. (1965) Atrial fibrillation in throtoxicosis treated with radioiodine. Postgrad. med. J. 41, 663.

SVEDMYR, N. (1966) Studies on the relationships between some metabolic effects of thyroid hormones and catecholamines in animals and man. Acta physiol. scand. 63, Suppl. 274.

SVEDMYR, N. \& WALDECK, B. (1965) The effect of 1-thyroxine treatment on the metabolism of $3 \mathbf{H}$ labelled catecholamines in the rat. Acta pharmacol. toxicol. 23, 325.
TUTTLE, R.R. \& INNES, I.R. (1966) Interaction of pronethanol and ouabain in cardiac rhythm and automaticity. $J$. Pharmacol. exp. Ther. 153, 211.

VAughaN Williams, E.M. (1966) Mode of action of $\beta$-adrenergic blocking agents. Amer. J. Cardiol. 18, 399.

Waldstein, S.S., West, G.H., LeE, W.Y. \& Bronsky, D. (1964) Guanethidine in hyperthyroidism. J. Amer. med. Ass. 189, 609.

Williamson, J.R. (1966) Metabolic effects of epinephrine in the perfused rat heart. Mol. Pharm. 2, 206.

Wilson, W.R., Theilen, E.O. \& Fletcher, F.W. (1964) Pharmacodynamic effects of $\beta$-adrenergic receptor blockade in patients with hyperthyroidism. J. clin. Invest. 43, 1697.

Wisewell, J.G., Hurwitz, G.E., Coronho, V., Bing, O.H.L. \& CHILD, D.L. (1963) Urinary catecholamines and their metabolites in hyperthyroidism and hyopthyroidism. J. clin. Endocr. 123, 1102. 